\title{
Who Are These Guys? An Exploration of Patterns of Parenting Problems Among Fathers Who Have Maltreated Their Children
}

\author{
Laura-Lynn Stewart and Katreena Scott \\ University of Toronto
}

\begin{abstract}
Despite the high prevalence of father-perpetrated maltreatment, relatively little empirical attention has been given to fathers who abuse and/or neglect their children. The current study explored the dynamics of harmful father-child interaction that may underlie fathers' risk for perpetrating child maltreatment. Data derived from structured interviews of 121 maltreating fathers were used to discern differential patterns of abuse-related problems in parenting. Results show that a minimum of half the fathers showed problems in each of the following areas: emotional unavailability, unresponsiveness, and neglect; negative attributions and misattributions to the child (including hostility, denigration and rejection); developmentally inappropriate or inconsistent interactions (including exposure to domestic violence); and failure to recognize or acknowledge the child's individuality and psychological boundary. These interview-rated difficulties were consistent with expected patterns of demographic risk and self-reported psychosocial difficulties. When considered together in a cluster analysis, groups of abusive fathers emerged with low (37.0\%), moderate (38.4\%), and severe (24.6\%) levels of problems across dimensions of harmful parent-child interactions. Results are discussed in terms of assessment and intervention needed to address father-perpetrated maltreatment.
\end{abstract}

Keywords: child abuse, maltreatment, father, domestic violence, emotional abuse, cluster analysis

Laura-Lynn Stewart, Department of Applied Psychology and Human Development, University of Toronto; Katreena Scott, Department of Applied Psychology and Human Development, University of Toronto.

Laura-Lynn Stewart currently works with the Child Protection Service Unit, BC Children's Hospital.

This research was supported, in part, by funding from the Centre for Research and Education on Violence Against Women and Children; and by a Social Sciences and Humanities Research Council (SSHRC) doctoral fellowship to Laura-Lynn Stewart.

Correspondence concerning this article should be addressed to Katreena Scott, Department of Applied Psychology and Human Development, University of Toronto, 252 Bloor St. W., Toronto, ON, M5S 1V6. Email: Katreena.Scott@utoronto.ca 


\section{RÉSUMÉ}

Malgré le très grand nombre de cas de maltraitance d'enfants attribuée à des pères, les chercheurs ont jusqu'à maintenant porté peu d'attention aux pères qui maltraitent ou négligent leurs enfants. Dans cette étude, nous explorons la dynamique de certaines interactions nocives entre des pères et leurs enfants qui sont associées aux risques que ces pères maltraitent leurs enfants. Nos données proviennent d'entrevues dirigées que nous avons réalisées avec 121 pères ayant maltraité leurs enfants. Grâce aux caractéristiques des pères que nous fournissent ces données, nous avons tenté de distinguer, parmi les participants, différents types de pères. Nos résultats indiquent qu'au moins la moitié des pères avaient des problèmes liés à chacun des type de caractéristiques dont notre analyse tient compte, soit : le manque d'affection, de l'insensibilité et de la négligence ; des conceptions négatives ou erronées de l'attitude des enfants qui entraînent de l'hostilité, du dénigrement et du rejet ; des interactions inappropriées ou incohérentes d'un point de vue développemental, dont l'exposition à de la violence familiale ; et l'incapacité à reconnaître ou à accepter l'individualité ou les limites psychologiques des enfants. L'évaluation de ces problèmes que les entrevues nous ont permis de faire correspond aux modèles qui tiennent compte des risques établis à partir de caractéristiques démographiques des pères ainsi que des difficultés psychosociales rapportées par les participants. Dans l'ensemble, l'analyse typologique montre que les pères abuseurs qui ont un problème lié aux différents types d'interactions nocives avec leurs enfants se répartissent selon les proportions suivantes : problèmes faibles $(37,0 \%)$, problèmes modérés $(38,4 \%)$ et problèmes graves $(24,6 \%)$. Nous analysons ces résultats pour indiquer des pistes de solution en matière d'évaluation et d'intervention.

Mots clés : violence envers les enfants, maltraitance, pères, violence familiale, violence psychologique, analyse typologique

\section{INTRODUCTION}

Fathers are responsible for perpetrating a significant proportion of child maltreatment (mothers and fathers are the ones responsible for $75 \%$ to $80 \%$ of all child maltreatment). National incidence studies in Canada and the United States find that fathers (including biological, step, and adoptive) are identified as perpetrators in approximately half the substantiated cases of maltreatment and predominate as perpetrators of injury-causing and lethal child abuse (B. Fallon, personal communication, November 12, 2013; Sinha, 2012; Trocmé et al., 2010; U.S. Department of Health and Human Services, 2013). Multinational homicide data also shows that a slight majority of family-related child homicides are committed by fathers (Lee \& Lathrop, 2010; Sidebotham, Bailey, Belderson, \& Brandon, 2011; Statistics Canada, 2009). Despite the high prevalence of father-perpetrated abuse among cases known to authorities, relatively little attention has been given to fathers who maltreat their children (Brown, Callahan, Strega, Walmsley, \& Dominelli, 2009; Dubowitz, 2006; Maxwell, Scourfield, Featherstone, Holland, \& Tolman, 2012; Strega et al., 2008; Zanoni, Warburton, Bussey, \& McMaugh, 2013). Most research has focused on the role of mothers in maltreatment or has utilized samples consisting of both mothers and fathers, without distinguishing which parent perpetrated the abuse (Featherstone \& Fraser, 2012; Phares, 1996; Pittman \& Buckley, 2006). This bias in the literature is problematic as it has not allowed for a complete and adequate examination of the context in which maltreatment occurs.

One of the ways we can advance our understanding of how best to prevent and/or intervene to end child maltreatment is by obtaining a more accurate characterization of maltreating fathers. Within the literature, fathers who abuse and neglect their children have been largely portrayed as a homogeneous group with a 
clearly defined set of shared negative characteristics. Clinical descriptions have focused on fathers' rigid, authoritarian parenting style, frequent use of power-assertive and coercive parenting strategies, and violent use of force (Bancroft \& Silverman, 2002; Harne, 2011; Kelly \& Wolfe, 2004). Emerging empirical studies have also treated abusive fathers as a homogeneous group by employing methodological designs that compare maltreating fathers against their nonabusive peers (Fox \& Benson, 2004; Pittman \& Buckley, 2006; Stover, Easton, \& McMahon, 2013). This lack of differentiation is in contrast to the more nuanced characterizations available for domestic violence perpetrators and maltreating mothers (Cavanaugh \& Gelles, 2005; Holtzworth-Munroe \& Stuart, 1994; Tolan, Gorman-Smith, \& Henry, 2006). To advance our understanding of maltreating fathers and contribute to our knowledge of how we can promote safe and healthy father-child relationships, the current study explored the ways in which maltreating fathers differ in the problematic dynamics that characterize their relationships with children.

\section{Child Maltreatment Typologies}

Researchers have advanced a number of models of heterogeneity in maltreating parents, based mostly on studies of mothers. Early attempts tended to focus on the personality characteristics of maltreating parents (e.g., Sloan \& Meier, 1983) or attempted to differentiate families on the basis of the type of abuse investigated (i.e., physical abuse versus neglect). As research in this area developed, researchers moved from typologies based on clinical impressions and referral information to those that relied on parenting attitudes and behaviours and that used standardized measures of assessment and statistical approaches to data analysis. These later models focused on parent-child dynamics hypothesized to be key factors in potentiating risk for maltreatment and, to the extent that they remain unremitted over time, propelling the parent towards increasingly abusive and neglectful behaviour. By focusing on these dynamics, it is expected that resulting typologies will help clinicians tailor their treatment approaches to the needs of specific parent-child dyads.

An early cluster model based on parent-child dynamics was presented by Oldershaw, Walters, and Hall (1989). On the basis of a cluster analysis of behavioural observation data, these researchers identified three subgroups of parents differentially described as "emotionally distant," "intrusive," and "hostile" in their interactions with children. Haskett and her colleagues extended this research in a number of studies, including self-reported attitudes along with observational data in their cluster analyses. Results revealed three subgroups similar to those found by Oldershaw and colleagues (i.e., detached, intrusive, and hostile), along with a fourth group (labelled "low negative") that had more positive and neutral behaviours and fewer negative behaviours than the sample as a whole (Haskett \& Smith Scott, 1996; Haskett, Smith Scott, Grant, Ward, \& Robinson, 2003; Haskett, Smith Scott, \& Ward, 2004).

Empirical examinations of clusters of problematic parent-child dynamics dovetail with developing theoretic models for conceptualizing child maltreatment. Of particular interest is the work of Danya Glaser $(2002,2011)$, who conceptualizes emotional maltreatment and harmful parent-child interactions more generally as violations of the key elements of children's psychosocial being. Using child psychological well-being needs as a starting point, Glaser has outlined five patterns of harmful parent-child interactions:

1. Emotional unavailability, unresponsiveness and neglect;

2. Negative attributions and misattributions to the child, including hostility, denigration and rejection; 
3. Developmentally inappropriate or inconsistent interactions, including exposure to domestic violence;

4. Failure to recognize or acknowledge the child's individuality and psychological boundary; and

5. Failing to promote child's social adaptation.

She further suggests that these patterns of harmful interaction may mediate, or explain, the harm caused by other forms of child abuse and neglect by primary caregivers, including physical abuse, neglect, and sexual abuse. To intervene with families, Glaser suggests a tiered model of assessment that includes identification of patterns of harmful caregiver-child interactions and intervention matched to the dysfunctional interaction that is driving harm to the child. There has been continued work in the United Kingdom to develop this framework and a recent government-funded evaluation of its utility for helping frontline workers recognize emotional abuse and neglect, as well as conceptualize the intervention needs of families presenting with a range of forms of maltreatment (Glaser, Prior, Auty, \& Tilki, 2012).

In addition to overlapping substantially with prior empirical clustering of physically abusive parents (in particular, categories 1, 2, and 4) (Oldershaw, Walters, \& Hall, 1989; Haskett et al., 2003; Haskett et al., 2004), each of the five problematic parent-child interaction patterns outlined by Glaser has been supported in empirical studies of risk factors for child maltreatment. Low levels of paternal warmth and involvement have been noted in samples of maltreating and at-risk fathers, as well as among fathers identified for perpetration of domestic violence (Brown, Cohen, Johnson, \& Salzinger, 1998; Holden \& Ritchie, 1991; Johnston \& Campbell, 1993). Negative parental attributions for child misbehaviour have long been implicated in risk for maltreatment among mothers and fathers (Milner, 2003; Stith et al., 2009). Specifically, mothers and fathers who abuse and neglect their children have been shown to be more likely than their nonabusing peers to see their children as difficult and to attribute their child's ambiguous and unruly behaviour to intentional deviance (Bugental, Blue, \& Cruzcosa, 1989; Bugental \& Happaney, 2000; Dadds, Mullins, McAllister, \& Atkinson, 2003). Glaser's third pattern of maladaptive parenting, developmentally inappropriate or inconsistent interactions, has been supported in studies of expectations of mothers (Hakman, Chaffin, Funderburk, \& Silovsky, 2009) and, to a lesser extent, fathers (Perry, Wells, \& Doran, 1983; Pittman \& Buckley, 2006). In addition, there is a great deal of research documenting the links between marital hostility, conflict, and domestic violence (also included in this category) and the risk of father-perpetrated physical and emotional maltreatment (e.g., Dixon, Hamilton-Giachritsis, Browne, \& Ostapuik, 2007; Edleson, 1999; Hartley, 2004; Salisbury, Henning, \& Holdford, 2009; Smith Slep \& O'Leary, 2005). Finally, problems related to weak parent-child psychological boundaries and failures to support children's social adaptation have been written about in many clinical descriptions of abusive fathers (e.g., Bancroft \& Silverman, 2002; Scott \& Crooks, 2004), but less often investigated empirically.

\section{Examining Problematic Dynamics in the Father-Child Relationship}

While the literature provides a foundation on which to build typologies of abusive fathers and beginning support for the relevance of Glaser's five parent-child dynamics to understanding fathers' risk for child maltreatment, questions remain with regard to whether or not these patterns of parenting characterize all abusive and neglectful fathers or if, as suggested by Glaser $(2002,2011)$, fathers might be more likely to present 
with a "driving," or primary problematic interaction. Also of interest is whether profiles of dysfunctional interaction show predictable relationships to other risk factors for maltreatment. Thus, the goal of the current study was to explore diversity in the dynamics that characterize abusive and neglectful father-child relationships. We hypothesized that multiple clusters would emerge, based on the predominant problem evidenced in fathers' relationships with their children, and independent of the specific form of abuse that was the basis for a father's referral. Resulting groups were compared on a large number of risk factors established in the literature (e.g., demographics, hostility, aggression, interpersonal reactivity, conflictual parent relationships) to further describe the groups that emerged.

\section{METHODS}

\section{Participants}

Participants in this study were recruited from a group intervention program for fathers who had abused or neglected a child. In total, a sample of 121 fathers was drawn from 15 intervention groups over a period of 1.5 years, with a research consent rate of $81 \%$. All of the intervention groups were run by Changing Ways, a community organization located in a mid-sized urban community in southwestern Ontario. Participating fathers ranged in age from 18 to 58 years, with an average age of $33(S D=8.31)$. The majority of fathers identified their ethnicity as Canadian (79\%). The remaining fathers identified themselves as European (8\%), African Canadian (4\%), First Nations (3\%), Latino/Hispanic (3\%), Middle Eastern (2\%), or Asian (1\%). Varying levels of education were reported among the fathers, with $46 \%$ reporting that they did not complete high school, 30\% reporting that they had received a high school diploma, and $24 \%$ reporting postsecondary education. Employment status was also variable: $47 \%$ of the fathers worked full-time, $14 \%$ worked part-time or for themselves, and 39\% were unemployed.

The majority of fathers reported that they were involved in the parenting of multiple children $(M=$ 3.07; range: one to 10 children). Almost all the fathers had at least one biological child ( $98 \%$; range: one to eight children), and nearly half reported being involved in the parenting of stepchildren (43\%; range: one to five children), grandchildren $(<1 \%)$, or foster children $(<1 \%)$. At the time of referral to treatment, $30 \%$ of the fathers were living with their child, $13 \%$ saw their child three to six times per week, $23 \%$ saw their child one to two times per week, and 34\% saw their child less than once a week. For the purpose of completing the self-report measures, fathers with more than one child were instructed to report on the child with whom they felt they had the most difficult relationship. Children about whom the fathers reported ranged in age from one month to 17 years and were an average age of $7(S D=4.84)$. The gender distribution among the children was relatively equal, with $46 \%$ of the children identified as male and $54 \%$ identified as female.

\section{Measures}

Demographic data. Basic demographic information, including the fathers' age, ethnicity, education, income, relationship status, number of children, and frequency of access to children, was collected via a pen-and-paper questionnaire. Fathers were also asked the frequency of their drinking and drunkenness over the past month. 
Referral data. The referral form in the fathers' clinical file was used to collect information about who referred fathers to the program and why. This form included the basic family information (e.g., number of children), source of referral (e.g., Children's Aid Society (CAS), probation, community mental health, addictions services, etc.), and two open-ended questions: one on the reason for referral and a second on the referrer's goals for fathers' participation (i.e., "what are you hoping this man will gain from the program?"). For all the fathers, family and referral source information was available; however, as a result of missing and incomplete referral forms, data on the reason for referral was only available for 69 of the 121 fathers $(57 \%)$.

Risk Interview Schedule for Children (RISC). To assess potential dynamics of abuse in the fatherchild relationship, participants were administered a semi-structured interview by clinical intake staff at the agency. This interview was first developed as part of a child maltreatment assessment protocol at a large children's hospital in Ontario (Scott \& Coolbear, 2001) and has been modified for use in both clinical (Eliav, 2008) and research settings (Scott \& Crooks, 2007; Stewart, 2004). Informed, in part, by Glaser's (2002) conceptual framework of psychological maltreatment, the interview taps the five areas of harmful parenting behaviour that she identified (as noted above). Each of the five constructs included in the RISC is represented in a separate subscale of the interview and is explored through a series of open-ended questions. Each respondent's answers are recorded verbatim and used to make a clinical judgment on the degree of health or dysfunction ( 1 = healthy development; 2 = average development/no concern; 3 = some concern; $4=$ moderate concern; 5 = high level of concern) in the parent-child relationship. Inter-rater agreement of $90 \%$ has been established for an earlier, but similar version of the RISC (Stewart, 2004). For the current study, inter-rater reliability was calculated by having a doctoral student rate each construct on the basis of the verbatim notes written by the clinician administering the interview. Agreement rate was slightly lower at $84 \%$, but still acceptable. When disagreements occurred, they were always within one point of rating and were resolved through consultation with the doctoral student rater and the agency clinician interviewer. Concurrent validity of RISC rating has also been established. RISC ratings have been shown to be related to several risk factors associated with abuse, including parenting stress (Stewart, 2004), poor appreciation of the impact of negative events on children (Barotas, 2004), decreased ability to accept responsibility for abusive behaviour (Barotas, 2004), rigidity, and problems with family members and others (Stewart, 2004). Moreover, the modified hospital-based version of the interview has been shown to reliably distinguish between groups at high and low risk for abuse and has been related to experts' judgment on the need to refer families to child protection services (Eliav, 2008).

Self-report Psychosocial Assessments. Fathers completed a package of self-report questionnaires to assess problems in generalized hostility and aggression, empathy, and parenting alliance. The Aggression Questionnaire (AQ) (Buss \& Perry, 1992), a 29-item self-report measure of hostility and aggression, was used to assess fathers' level of aggression. This measure produces a Total Aggression score (all items) and four subscale scores that measure: anger (seven items), hostility (eight items), verbal aggression (five items), and physical aggression (nine items). Higher scores are indicative of higher levels of aggression. Empirical studies have shown the AQ to have moderate to high internal consistency (Buss \& Perry, 1992; Gerevich, Bácskai, \& Czobor, 2007; Harris, 1997), adequate stability over time (Buss \& Perry, 1992; Harris, 1997), and good concurrent validity with other measures of anger, aggression, and hostility (Harris, 1997; Williams, Boyd, 
Cascardi, \& Poythress, 1996). To assess empathy, fathers completed the Interpersonal Reactivity Index (IRI) (Davis, 1983), a 28-item self-report measure designed to evaluate the cognitive and affective dimensions of empathy. Items are grouped into four seven-item scales that reflect different aspects of empathy: perspective taking, fantasy, empathetic concern, and personal distress, which can be summed to create a total score. Following the work of Francis and Wolfe (2008), items were modified in order to specifically appraise the father's approach to his child rather than to a friend or someone else (e.g., "I sometimes find it difficult to see things from [my child's] point of view"). Previous research has demonstrated strong internal reliability and good convergent and discriminant validity for the IRI (Davis, 1983). Finally, the fathers completed the Parenting Alliance Measure (PAM) (Abidin \& Konold, 1999) to assess their perceived child-rearing alliance with the children's mothers. This 20-item self-report is summed to yield a Total Parenting Alliance score and can be separated into two subscale scores assessing: communication and teamwork (17 items) and respect for the other parent's commitment and judgement (three items) (Konold \& Abidin, 2001). Higher scores are indicative of a stronger and more positive parenting alliance. Good internal consistency, test-retest reliability, and construct validity have been reported for this measure (Abidin \& Konold, 1999; Konold \& Abidin, 2001).

\section{Procedure}

The study was completed in accordance with the Tri-Council Policy Statement on Ethical Conduct for Research Involving Humans and was reviewed by the Education Ethics Review Committee (EERC) of the University of Toronto and by the community agency that was the site of recruitment. All of the fathers who completed intake for the program were informed of the study and given detailed information regarding the procedures and ethical issues related to participating. Clinically trained agency intake staff administered the RISC semi-structured interview to participating fathers, after which participants completed the self-report measures.

Data analyses were conducted in two phases. The first phase included an exploratory analysis of the demographic and background characteristics of the fathers, as well as an examination of the fathers' functioning in each of the RISC's five areas of potentially problematic parenting interaction. A combination of chi-square and analyses of variance (ANOVA) techniques was used to complete the bivariate analyses. The second phase examined heterogeneity among the fathers, using cluster analysis of ratings on the RISC measure. Cluster analysis was done with SLEIPNER 2.1, a specialized statistical package. Initial hierarchical clustering was performed using each of the available clustering methods in SLEIPNER (i.e., Ward's method, beta-flexible, group average, complete linkage, median, centroid, and single linkage) and the appropriate distance measures for each method (e.g., squared Euclidian and correlation). For each method/distance combination, the number of clusters extracted was based upon:

(a) the extent to which additional cluster solutions identified meaningful and relevant patterns;

(b) whether each successive cluster solution reduced the error sums of squares, accounted for increasing amounts of variance, and yielded acceptable coefficients of homogeneity; and

(c) whether a minimum of $5 \%$ of the sample was represented in each cluster.

Once the initial cluster solution was determined, the Relocate Module was then applied to the chosen solution to allow for adjustments in cluster membership. 


\section{RESULTS}

\section{Descriptive Information}

As seen in Table 1, the majority of the 121 participants in this study were referred by either the Children's Aid Society (58\%) or probation and court services (25\%). Among fathers with complete information on the reason for referral $(n=69)$, the largest percentage of fathers $(60.9 \%)$ were referred for emotional abuse via exposure of their children to domestic violence, either alone or in combination with other forms of abuse. Fewer fathers were referred for reasons related to physical abuse (24.6\%), emotional/verbal abuse (20.3\%), sexual abuse (7.2\%), and neglect (4.3\%). Referrers also fairly frequently identified fathers' addictions (29.0\%) and mental health $(21.7 \%)$ as reasons for referral.

Examination of the RISC ratings found expected variability in levels of problematic parenting among fathers. The distribution of ratings across dynamics indicated that the most frequent area of concern (some concern, moderate concern, and high level of concern) among fathers was lack of emotional connection to their children (72.8\%), followed by problems with psychological boundaries $(67.6 \%)$, negative attributions and misattributions (60.1\%), and developmentally inappropriate interactions, mostly exposure of the child to interparental hostility $(58.2 \%)$. The area with the least noted concerns was failure to promote children's social adaptation (33.9\%).

Table 1

Referral Source and Reason for Referral

\begin{tabular}{lcc}
\hline Characteristic & $n$ & $\%$ \\
\hline Referral source $(n=121)$ & & \\
Children's Aid Society & 70 & 57.85 \\
Probation/court order & 30 & 24.79 \\
Community mental health worker & 7 & 5.78 \\
Batterer intervention program & 6 & 4.95 \\
Self-referral & 6 & 4.95 \\
Other (i.e., physician, female partner) & 2 & 1.65 \\
& & \\
Reason for referral (categories may co-occur) $(n=69)$ & & \\
Domestic violence & 42 & 60.87 \\
Addiction & 20 & 28.98 \\
Physical abuse & 17 & 24.64 \\
Mental health concerns & 15 & 21.74 \\
Emotional abuse & 14 & 20.29 \\
Denial of impact on children & 8 & 11.59 \\
Legal implications & 6 & 8.69 \\
Parenting deficit & 6 & 8.69 \\
Sexual abuse & 5 & 7.24 \\
Neglect & 3 & 4.34 \\
\hline
\end{tabular}




\section{Patterns of Heterogeneity}

To gain further insight into the heterogeneity in this population of fathers, each of the five areas of parent-child psychosocial functioning measured by the RISC was explored in detail by correlating each of the demographic (i.e., father's age, child's age, frequency of alcohol intake, frequency of access, number of children) and self-reported psychosocial (aggression/hostility, empathy, and parenting alliance) variables with ratings on the RISC. This yielded a number of interesting patterns of relationships (see Table 2). The clearest pattern was noted for negative attributions and misattributions to the child, where higher levels of problem dynamics in this area were related to higher levels of self-reported general aggression $[r(76)=.35$, $p=.002]$, including verbal aggression $[r(76)=.28, p=.014]$, anger $[r(76)=.33, p=.004]$, and hostility towards others $[r(76)=.42, p=.000]$, as well as more frequent alcohol consumption $[r(78)=.34, p=.002]$.

Table 2

Exploratory Correlation Analyses Examining the Relationships Between Risk Ratings, Sample Characteristics, and Psychosocial Variables

\begin{tabular}{|c|c|c|c|c|c|}
\hline \multirow[t]{2}{*}{ Sample Characteristic } & \multicolumn{5}{|c|}{ RISC Construct } \\
\hline & $\begin{array}{c}\text { Emotional } \\
\text { Unavailability }\end{array}$ & $\begin{array}{l}\text { Negative } \\
\text { Attribution }\end{array}$ & $\begin{array}{c}\text { Inappropriate } \\
\text { Interactions (DV) }\end{array}$ & $\begin{array}{c}\text { Psychological } \\
\text { Boundaries }\end{array}$ & $\begin{array}{c}\text { Social } \\
\text { Adaptation }\end{array}$ \\
\hline \multicolumn{6}{|l|}{ Demographic } \\
\hline Father's age & -.02 & -.02 & .02 & .00 & $.24^{*}$ \\
\hline Child's age & $.23^{*}$ & .19 & .13 & .14 & $.32 * *$ \\
\hline Number of children & .12 & .11 & -.10 & .01 & .13 \\
\hline Frequency of visits & .19 & -.02 & .06 & .23 & -.02 \\
\hline Alcohol intake & .17 & $.34 * *$ & $.40 * *$ & -.05 & .11 \\
\hline \multicolumn{6}{|l|}{ Psychosocial Variables } \\
\hline \multicolumn{6}{|l|}{ Aggression } \\
\hline Physical & .04 & .22 & $.24 * *$ & -.04 & .05 \\
\hline Verbal & .12 & $.28^{*}$ & .17 & .06 & -.03 \\
\hline Anger & .11 & $.33^{* *}$ & .07 & .02 & .00 \\
\hline Hostility & $.23^{*}$ & $.42 * *$ & $.23 *$ & .15 & .13 \\
\hline Total & .13 & $.35^{* *}$ & .21 & .04 & .06 \\
\hline \multicolumn{6}{|l|}{ Interpersonal reactivity } \\
\hline Perspective taking & .05 & -.15 & -.02 & $-.30^{*}$ & -.12 \\
\hline Fantasy & -.14 & .15 & -.09 & .02 & .08 \\
\hline Empathy & -.09 & -.17 & $-.33^{*}$ & .12 & -.11 \\
\hline Distress & -.13 & .27 & -.10 & $-.33^{*}$ & .12 \\
\hline \multicolumn{6}{|l|}{ Parenting alliance } \\
\hline Communication & -.02 & -.04 & $-.29^{*}$ & -.13 & -.06 \\
\hline Respect & -.19 & -.14 & -.19 & -.12 & -.03 \\
\hline Total & -.06 & -.06 & $-.29^{*}$ & -.14 & -.06 \\
\hline
\end{tabular}

Notes.

$\mathrm{DV}=$ domestic violence.

${ }^{*} p<.05 .{ }^{* *} p<.01 . * * * p<.001$. 
RISC ratings indicating problems of maintaining developmentally appropriate interactions (mostly exposure of the child to hostile or abusive interparental relations) also showed predictable relations to higher frequencies of alcohol intoxication $[r(77)=.40, p=.000]$, higher self-reported physical aggression $[r(75)=.24, p=$ $.042]$, aggressive hostility towards others $[r(75)=.23, p=.05]$, weaker parenting alliances $[r(67)=-.29, p=$ $.019]$, problems communicating with the mother of their child $[r(67)=-.29, p=.017]$, and difficulties with empathy for their child $[r(53)=-.33, p=.016]$. Ratings of difficulties in the area of promoting their child's social adaptation were related only to age, with greater problems noted for older fathers $[r(73)=.24, p=$ $.039]$ and older children $[r(74)=.32, p=.006]$. Interviewer rating of problematic abuse dynamics in the area of failures to respect children's individuality and psychological boundary were related to deficits in selfreported empathy in the areas of both perspective taking $[r(44)=-.30, p=.048]$ and experiencing distress in interpersonal situations $[r(47)=-.33, p=.025]$. Finally, ratings of difficulties in emotional connection, the most commonly rated area of difficulty, showed few relations to self-reported problems, with significant relations only with children's age (less connection at higher ages) $[r(81)=.23, p=.04]$ and fathers' generalized hostility $[r(77)=.23, p=.04]$.

\section{Cluster Analysis on RISC Ratings}

Following from these analyses, ratings of fathers on each of the RISC's five problem domains were entered into a cluster analysis. Results were consistent across methods in identifying a similar three-cluster solution, and the model derived using the weighted average method was retained. Relocation analysis resulted in a total of 21 cases of moved groups, and the resulting solution had good properties (i.e., coefficients of homogeneity, sample size). Mean scores on each RISC dimension for each group are presented in Table 3. As expected, the groups differed significantly across all of the interview domains; however, differences did not correspond to identifying a primary or driving category of problematic relationships, or to a specific reason for referral. Rather, the three clusters varied in terms of severity and generality of problems in the father-child relationship. Fathers in the first cluster (37.0\%) were rated as generally healthy across all of the interview domains, suggesting "low" levels of problematic dynamics in the parent-child relationship. These fathers were rated as being more emotionally available, less hostile towards their children, better at maintaining parent-child psychological boundaries, and less likely to expose their children to developmentally inappropriate interactions than fathers in Clusters 2 and 3. They were also rated as promoting more appropriate social adaptation than fathers in Cluster 3. Examination of the scores obtained by the fathers in Cluster 2 (38.4\%) indicated a "moderate" level of concern regarding the relationship dynamics in the father-child relationship. Within the cluster, fathers had somewhat greater problems with emotional connection, psychological boundaries, developmentally appropriate interaction, and negative attributions. When compared to the other clusters, fathers in Cluster 2 differed significantly from the low-problem fathers in Cluster 1 in that they had greater difficulties in the areas of emotional connection, developmentally appropriate interactions, negative attributions, and problems with psychological boundaries. Finally, fathers in Cluster 3 (24.6\%) had the most "severe" problematic dynamics in their relationships with children. In comparison to fathers in both the low and moderate clusters, these fathers were rated as having greater problems in all five areas measured by the RISC. Particularly notable about this group was the lack of emotional connection to their children. 
Table 3

RISC Mean Scores on Cluster Variables for Low, Moderate, and Severe Clusters

\begin{tabular}{lcccc}
\hline Cluster Variables & $\begin{array}{c}\text { Low }(37.0 \%) \\
M(S D)\end{array}$ & $\begin{array}{c}\text { Moderate }(38.4 \%) \\
M(S D)\end{array}$ & $\begin{array}{c}\text { Severe }(24.6 \%) \\
M(S D)\end{array}$ & $F$ \\
\hline Emotional unavailability & $1.96(0.76)^{\mathrm{bc}}$ & $3.07(0.60)^{\mathrm{ac}}$ & $4.17(0.71)^{\mathrm{ab}}$ & $56.03^{* * *}$ \\
Negative attribution & $2.19(0.56)^{\mathrm{bc}}$ & $2.61(0.69)^{\mathrm{ac}}$ & $3.72(0.67)^{\mathrm{ab}}$ & $32.28^{* * *}$ \\
Inappropriate interactions & $1.96(0.65)^{\mathrm{bc}}$ & $3.00(0.86)^{\mathrm{ac}}$ & $3.56(0.70)^{\mathrm{ab}}$ & $26.78^{* * *}$ \\
Psychological boundaries & $2.22(0.58)^{\mathrm{bc}}$ & $3.07(0.54)^{\mathrm{ac}}$ & $3.56(0.70)^{\mathrm{ab}}$ & $29.33^{* * *}$ \\
Social adaptation & $2.00(0.48)^{\mathrm{c}}$ & $2.25(0.52)^{\mathrm{c}}$ & $3.28(1.02)^{\mathrm{ab}}$ & $21.33^{* * *}$ \\
RISC interview total score & $10.33(1.33)^{\mathrm{bc}}$ & $14.00(1.25)^{\mathrm{ac}}$ & $18.28(1.41)^{\mathrm{ab}}$ & $197.36^{* * *}$ \\
\hline
\end{tabular}

Notes.

$* p<.05 . * * p<.01 . * * * p<.001$.

Values that differ significantly from each other are marked with matching letters.

To determine the extent to which the empirically derived groupings differentiated fathers on demographic and psychosocial variables, a series of ANOVAs were done to compare clusters on demographic and psychosocial variables (results not shown). Surprisingly, and contrary to hypotheses, significant differences emerged on only one variable - child age - with fathers in the severe group having children who were significantly older than fathers in the low and moderate groups $[F(2,72)=3.57, p=.03]$. For all other demographic variables, including reason for referral and level of contact with children, and for all self-reported psychosocial (aggression/hostility, empathy, and parenting alliance) variables, no significant differences were noted across clusters.

\section{DISCUSSION}

The current study explored ways in which maltreating fathers varied in the problems that characterized their relationships with their children. Five patterns of harmful parent-child interaction were explored:

1. Emotional unavailability, unresponsiveness and neglect;

2. Negative attributions and misattributions to the child, including hostility, denigration and rejection;

3. Developmentally inappropriate or inconsistent interactions, including exposure to domestic violence;

4. Failure to recognize or acknowledge the child's individuality and psychological boundary; and

5. Failing to promote child's social adaptation.

For all patterns except failing to promote children's social adaptation, problems were noted for at least half of the fathers, with particularly high rates in the areas of emotional connection and psychological boundaries. Consistent and expected relations were found between patterns of harmful parent-child (interviewer-rated 
RISC scores) and self-reported difficulties in most domains. For example, interviewer ratings of problems in respecting children's individuality and psychological boundaries were related to deficits in self-reported empathy for the child. However, contrary to the hypothesis that fathers would cluster according to a predominant dynamic of problematic parent-child interaction, analyses revealed that maltreating fathers were most clearly differentiated by the degree of the severity of dysfunction (i.e., low, moderate, or high) in their relationships with their children. In combination, then, results support the need to consider both the severity of problems evidenced by fathers and the specific pattern of difficulties to be addressed.

Considering severity first, exploration of the ways in which maltreating fathers vary in the relational dynamics that characterize their maltreatment revealed three clearly differentiated groups. Fathers in the "low" severity cluster were rated as generally healthy across all of the parent-child dynamics examined. In comparison to "low" fathers, those in the "moderate" group had greater difficulties in the areas of emotional connection, negative attributions (hostility and blame), failure to recognize children's psychological boundaries, and developmentally inappropriate interactions (most often, exposure to domestic violence). No significant differences were observed between low and moderate fathers in promoting children's social adaptation. Fathers in the "severe" group had the greatest difficulties in all five dynamics examined and were the only fathers reported to have problems related to failures to promote children's social adaptation. Also particularly notable about this group was their very low level of emotional availability to their children.

Although fathers might best be clustered in terms of severity, fathers' self-reported problems did not vary consistently across clusters. Rather, a closer analysis of problem areas revealed domain-specific and theoretically predictable patterns of difficulties. Considering each area in turn, interviewer ratings of father's negative attributions and hostility towards their children were significantly related to fathers' self-reported anger, aggression, and hostility. These findings are consistent with theoretical models of risk for child abuse that emphasize the importance of negative affectivity and coercive cycles of negative interaction between fathers and children (Milner, 2003). For such problems, strongest support is available for interventions able to address cognitive attribution errors and increase parents' skills in avoiding coercive interactions, such as Parent-Child Interaction Therapy (PCIT) (Chaffin et al., 2004) or The Incredible Years programs (Reid, Webster-Stratton, \& Hammond, 2003).

A different pattern of self-reported difficulty was noted for fathers rated as having problems related to exposure of their children to developmentally inappropriate interactions, most often interparental hostility and violence. Consistent with the literature on domestic violence as a risk factor for child abuse, problems in this area were noted for almost $60 \%$ of the sample (Cavanagh, Dobash, \& Dobash, 2007; Coohey, 2006; Dixon et al., 2007; Hartley, 2004; Yampolskaya, Greenbaum, \& Berson, 2009). Interviewer-rated problems in this area were related to fathers' self-reported difficulties in maintaining respectful and open communication with their children's mothers, as well as with generalized anger and hostility, more frequent alcohol use, and lower levels of empathy for their children. Developmentally inappropriate exposure to marital hostility/ violence covaried as well with other problematic father-child dynamics, with incrementally higher levels of problems in this domain in the moderate and severe clusters of fathers. Consistent with the prevalence of this problematic dynamic, a number of theorists have suggested that respectful coparenting be a core target of intervention for abusive fathers (Scott \& Mederos, 2011; Stover, 2013); however, there is less evidence yet for the type of intervention likely to be most helpful. Glaser (2011) has suggested the intervention begin 
with traditional domestic violence intervention programs, Stover (2013) proposes dyadic sessions with children's mothers, and Scott and Crooks (2004) suggest group-based sessions with fathers focused on promoting respectful and nonabusive relationships with children's mothers.

A third common area of harmful parenting concerned fathers' recognition of their children's individuality and psychological boundaries. Problems with boundaries, in turn, showed unique correlations with self-reported empathetic perspective taking and distress. Problems with boundaries among batterers have been described, but mostly in respect to using children to gain information about their mothers post separation or as a form of parentification (Bancroft \& Silverman, 2002; Harne, 2011). Other forms of boundary violations have been less often described. Given the prevalence of this finding and its unique relation to self-reported empathy, more research is needed to describe and understand the types of boundary violations most common among abusive fathers and to consider the type of intervention needed to address this harmful parenting dynamic.

Finally, the most prevalent problematic fathering dynamic found among this sample of maltreating fathers was a lack of emotional connection to their children, with nearly three-quarters of the fathers describing relationships characterized by emotional unavailability and unresponsiveness. The observed problems with responsiveness are in contrast to commonly held stereotypes that tend to emphasize fathers' rigidity and harshness. While not absent from descriptions (e.g., Scott \& Crooks, 2004; Perel \& Peled, 2008), fathers' lack of responsiveness and emotional connection is not often identified as a risk factor in and of itself. In these results, a lack of emotional connection appeared to act as a backdrop to virtually all other forms of abuse, significantly differentiating both the moderate and high severity clusters from fathers grouped as low in abuse-related parenting dynamics. Such results have substantial implications for intervention, pointing to the need to provide fathers with opportunities to build strong emotional connections with their children. Once again, this is an area of intervention that has been less well charted. Intervention likely needs to begin by increasing fathers' awareness of problems in emotional connection which, in our experience, often dovetails with fathers taking responsibility for past harmful and abusive behaviours. Following such awareness, fathers may need to develop skills for responsive parenting in general, or may need support in more limited and specific areas (e.g., discussion of separation or CAS involvement).

Consideration of the cluster and problem-dynamic findings together suggests that a range of intervention options are necessary. Such interventions need to vary by intensity, with more basic education and skills training in responsiveness for the low group, but more extensive parenting intervention for the moderate- and high-problem groups. Moreover, for these groups, it does not appear that intervention focused on any one dynamic of problems will be sufficient. Rather, a series of differentially focused, targeted interventions might be required. Of concern, results suggest varying levels of services are not currently being offered; neither the reason for referral nor the level of father-child contact varied by cluster. This finding raises important questions about the sensitivity of child protection services to the severity and nature of problem dynamics in fathers' relationships with their children - areas that would be important to explore in future research.

\section{Strengths and Limitations of the Research}

Findings from the current study should be interpreted within the context of several methodological limitations. Given the exploratory design of the study, a large number of statistical analyses were performed 
to fully explore the presenting characteristics of the sample. Although these significantly increased the likelihood of type 1 error, corrections were not applied because the primary intent of the study was to identify potential relationships among the variables for the purpose of future research. Caution is therefore needed when interpreting the results, as some of the significant findings may be spurious. A second limitation of the study relates to selection bias: a problem considered endemic to clinical or risk-based samples (Coohey, 2006; Dubowitz et al., 2001). Participating fathers were recruited from a group intervention program for fathers who had abused or neglected a child. Most fathers were referred to this group by a child protection worker or a probation officer. Moreover, fathers were asked to report on the child with whom they had the most difficult relationship. Thus, results are most generalizable to fathers whose abuse has been officially recognized and to dynamics specific to fathers' relationships with the child they deem most difficult. Results may not be generalizable across fathers' relationships with their children or to maltreating fathers whose abuse has escaped detection (Guterman \& Lee, 2005). Future research would benefit from the use of a more general sample of abusive fathers and from data collection strategies that included information from fathers, mothers and children on fathers' relationships with each of their children. Finally, it is important to note that the theoretical model used to assess patterns of dysfunctional parent-child interaction was designed to capture emotional/psychological abuse. Although it may be extended to understanding parenting associated with other forms of maltreatment, factors beyond the caregiver-child relationship may also be relevant and critical to understanding heterogeneity.

\section{Conclusion}

This study is one of the first to directly assess heterogeneity among maltreating fathers. A combination of semistructured clinical interviews and self-report methods was also used, thereby providing valuable insight into fathers' views and perspectives on their relationships with their children. Results from this work help further our understanding of maltreating fathers and their relationships with children. By uncovering diversity in problematic parent-child dynamics of these fathers, important new insight has been gained into paternal risk for maltreatment. To more fully understand maltreating fathers and their relationships with children, continued attention needs to be given to the differences that exist among these fathers to better understand the different motivations for abusive behaviour, co-occurring psychological or mental health concerns that impact their parenting, and the different treatment needs that are paramount to intervention. It is hoped that with such knowledge clinicians will be in a better position to identify problematic relationships earlier and more appropriately target intervention, thereby preventing incidents of abuse and neglect in the father-child relationship.

\section{REFERENCES}

Abidin, R. R., \& Konold, T. R. (1999). Parenting Alliance Measure professional manual. Odessa, FL: Psychological Assessment Resources.

Bancroft, L., \& Silverman, J. G. (2002). The batterer as parent: Addressing the impact of domestic violence on family dynamics. Thousand Oaks, CA: Sage.

Barotas, K. (2004). Fathers 'perceptions of their children's exposure to unhealthy parenting: The importance of acknowledging responsibility and appreciating impact. (Unpublished master's thesis). University of Toronto, Canada. 
Brown, L., Callahan, M., Strega, S., Walmsley, C., \& Dominelli, L. (2009). Manufacturing ghost fathers: The paradox of father presence and absence in child welfare. Child and Family Social Work, 14, 25-34. doi:10.1111/j.1365-2206.2008.00578.x

Brown, J., Cohen, P., Johnson, J. G., \& Salzinger, S. (1998). A longitudinal analysis of risk factors for child maltreatment: Findings of a 17-year prospective study of officially recorded and self-reported child abuse and neglect. Child Abuse \& Neglect, 22, 1065-1078. doi:10.1016/S0145-2134(98)00087-8

Bugental, D. B., Blue, J., \& Cruzcosa, M. (1989). Perceived control over caregiving outcomes: Implications for child abuse. Developmental Psychology, 26, 631-638. doi:10.1037/0012-1649.25.4.532

Bugental, D. B., \& Happaney, K. (2000). Parent-child interaction as a power contest. Journal of Applied Developmental Psychology, 21, 267-282. doi:10.1016/S0193-3973(99)00038-6

Buss, A. H., \& Perry, M. (1992). The Aggression Questionnaire. Journal of Personality \& Social Psychology, 63, 452-459. doi:10.1037/0022-3514.63.3.452

Cavanagh, K., Dobash, R. E., \& Dobash, R. P. (2007). The murder of children by fathers in the context of child abuse. Child Abuse \& Neglect, 31, 731-746. doi:10.1016/j.chiabu.2006.12.016

Cavanaugh, M. M., \& Gelles, R. J. (2005). The utility of male domestic violence offender typologies: New directions for research, policy and practice. Journal of Interpersonal Violence, 20, 155-166. doi:10.1177/0886260504268763

Chaffin, M., Silovsky, J. F., Funderburk, B., Valle, L. A., Brestan, E. V., Balachova, T., ... Bonner, B. L. (2004). ParentChild Interaction Therapy with physically abusive parents: Efficacy for reducing future abuse reports. Journal of Consulting and Clinical Psychology, 72, 500-510. doi:10.1037/0022-006X.72.3.500

Coohey, C. (2006). Physically abusive fathers and risk assessment. Child Abuse \& Neglect, 30, 467-480. doi:10.1016/j. chiabu.2004.10.016

Dadds, M. R., Mullins, M. J., McAllister, R. A., \& Atkinson, E. (2003). Attributions, affect and behaviour in abuse-risk mothers: A laboratory study. Child Abuse \& Neglect, 27, 21-45. doi:10.1016/S0145-2134(02)00510-0

Davis, M. H. (1983). Measuring individual differences in empathy: Evidence for a multidimensional approach. Journal of Personality and Social Psychology, 44, 113-126. doi:http://dx.doi.org/10.1037/0022-3514.44.1.113

Dixon, L., Hamilton-Giachritsis, C., Browne, K., \& Ostapuik, E. (2007). The co-occurrence of child and intimate partner maltreatment in the family: Characteristics of the violent perpetrators. Journal of Family Violence, 22, 675-689. doi:10.1007/s10896 -007-9115-x

Dubowitz, H. (2006). Where's dad? A need to understand father's role in child maltreatment. Child Abuse \& Neglect, 30, 461-465. doi:10.1016/j .chiabu.2006.04.002

Dubowitz, H., Black, M., Cox, C., Kerr, M., Litrownik, A., Radhakrishna, A., .. Runyan, D. K. (2001). Father involvement and children's functioning at age 6 years: A multisite study. Child Maltreatment, 6, 300-309. doi:10.1177 $/ 1077559501006004003$

Edleson, J. L. (1999). The overlap between child maltreatment and woman battering. Violence Against Women, 5 , 134-154. doi:10.1177/107780129952003

Eliav, J. T. (2008). Comprehensive evaluation of a three-component psychosocial protocol used to guide decisionmaking for child maltreatment concerns, developed for medical settings (Unpublished doctoral dissertation). University of Toronto, Canada.

Featherstone, B., \& Fraser, C. (2012). Working with fathers around domestic violence: Contemporary debates. Child Abuse Review, 21, 255-263. doi:10.1002/car.2221

Fox, G. L., \& Benson, M. L. (2004). Violent men, bad dads? Fathering profiles of men involved in intimate partner violence. In R. D. Day \& M. E. Lamb (Eds.), Conceptualizing and measuring father involvement (pp. 359-384). Mahwah, NJ: Lawrence Erlbaum.

Francis, K. J., \& Wolfe, D. A. (2008). Cognitive and emotional differences between abusive and non-abusive fathers. Child Abuse \& Neglect, 32, 1127-1137. doi:10.1016/j .chiabu.2008.05 .007

Gerevich, J., Bácskai, E., \& Czobor, P. (2007). The generalizability of the Buss-Perry Aggression Questionnaire. International Journal of Methods in Psychiatry Research, 16, 124-136. doi:10.1002/mpr.221

Glaser, D. (2002). Emotional abuse and neglect (psychological maltreatment): A conceptual framework. Child Abuse \& Neglect, 26, 697-714. doi:10.1016/S0145-2134(02)00342-3

Glaser, D. (2011). How to deal with emotional abuse and neglect-Further development of a conceptual framework (FRAMEA). Child Abuse \& Neglect, 35, 866-875. doi:10.1016/j.chiabu.2011.08.002 
Glaser, D., Prior, V., Auty, K., \& Tilki, S. (2012). Does training in a systematic approach to emotional abuse improve the quality of children's services? Research Brief, Department for Education, London, UK.

Guterman, N. B., \& Lee, Y. (2005). The role of fathers in risk of physical child abuse and neglect: Possible pathways and unanswered questions. Child Maltreatment, 10, 136-149. doi:10.1177 /1077559505274623

Hakman, M., Chaffin, M., Funderburk, B., \& Silovsky, J. F. (2009). Change trajectories for parent-child interaction sequences during parent-child interaction therapy for child physical abuse. Child Abuse \& Neglect, 33, 461-470. doi:10.1016/j.chiabu.2008.08.003

Harne, L. (2011). Violent fathering and the risk to children: The need for change. Bristol, UK: The Policy Press.

Harris, J. A. (1997). A further evaluation of the Aggression Questionnaire: Issues of validity and reliability. Behaviour Research and Therapy, 35, 1047-1053. doi:10.1016/S0005-7967(97)00064-8

Hartley, C. (2004). Severe domestic violence and child maltreatment: Considering child physical abuse, neglect, and failure to protect. Children and Youth Services Review, 26, 373-392. doi:10.1016/j .childyouth.2004.01 .005

Haskett, M. E., \& Smith Scott, S. (1996, August). Subtyping of maltreating parents and their children: A step toward refining family-based interventions. In L. Peterson (Chair), Beyond parenting skills: Parent-child relationships and child maltreatment. Symposium conducted at the 104th Annual Convention of the American Psychological Association, Toronto, Ontario, Canada.

Haskett, M. E., Smith Scott, S., Grant, R., Ward, C. S., \& Robinson, C. (2003). Child-related cognitions and affective functioning of physically abusive and comparison parents. Child Abuse \& Neglect, 27, 663-686. doi:10.1016/ S0145-2134(03)00103-0

Haskett, M. E., Smith Scott, S., \& Ward, C. S. (2004). Subgroups of physically abusive parents based on cluster analysis of parenting behavior and affect. The American Journal of Orthopsychiatry, 74, 436-447. doi:10.1037/0002-9432.74.4.436

Holden, G. W., \& Ritchie, K. L. (1991). Linking extreme marital discord, child rearing, and child behavior problems: Evidence from battered women. Child Development, 62, 311-327. doi:10.2307/1131005

Holtzworth-Munroe, A., \& Stuart, G. L. (1994). Typologies of male batterers: Three subtypes and the differences among them. Psychological Bulletin, 116, 476-497. doi:10.1037//0033-2909.116.3.476

Johnston, J. R., \& Campbell, L. E. G. (1993). Parent-child relationships in domestic violence families disputing custody. Family and Conciliation Courts Review, 31, 282-298. doi:10.1111/j.174-1617.1993.tb00305.x

Kelly, T., \& Wolfe, D. A. (2004). Advancing change with maltreating fathers. Clinical Psychology: Science and Practice, 11, 116-119. doi:10.1093/clipsy/bph060

Konold, T. R., \& Abidin, R. R. (2001). Parenting alliance: A multifactor perspective. Assessment, 8, 47-65. doi:10.1177/107319110100800105

Lee, C. K., \& Lathrop, S. L. (2010). Child abuse-related homicides in New Mexico: A 6-year retrospective review. Journal of Forensic Sciences, 55, 100-103. doi:10.1111/j.1556-4029.2009.01253.x

Maxwell, N., Scourfield, J., Featherstone, B., Holland, S., \& Tolman, R. (2012). Engaging fathers in child welfare services: A narrative review of recent research evidence. Child and Family Social Work, 17, $160-169$. doi:10.1111/j.1365-2206.2012.00827.x

Milner, J. S. (2003). Social information processing in high-risk and physically abusive parents. Child Abuse \& Neglect, 27, 7-20. doi:10.1016/S0145-2134(02)00506-9

Oldershaw, L., Walters, G. C., \& Hall, D. K. (1989). A behavioral approach to the classification of different types of physically abusive mothers. Merrill-Palmer Quarterly, 35, 255-279. Retrieved from http://www.jstor.org.my access.library.utoronto.ca/stable/23086372

Perel, G., \& Peled, E. (2008). The fathering of violent men. Violence Against Women, 14, 457-482. doi: $10.1177 / 1077801208314846$

Perry, M. A., Wells, E. A., \& Doran, L. D. (1983). Parent characteristics in abusing and nonabusing families. Journal of Clinical Child Psychology, 12, 329-336. doi:10.1080/15374418309533153

Phares, V. (1996). Conducting nonsexist research, prevention, and treatment with fathers and mothers: A call for change. Psychology of Women Quarterly, 20, 55-77. doi:10.1111/j.1471-6402.1996.tb00665.x

Pittman, J. F., \& Buckley, R. R. (2006). Comparing maltreating fathers and mothers in terms of personal distress, interpersonal functioning and perceptions of family climate. Child Abuse \& Neglect, 30, 481-496. doi:10.1016/j. chiabu.2004.10.017 
Reid, M. J., Webster-Stratton, C., \& Hammond, M. (2003). Follow-up of children who received the Incredible Years intervention for oppositional-defiant disorder: Maintenance and prediction of 2-year outcome. Behavior Therapy, 34, 471-491. doi:10.1016/S0005-7894(03)80031-X

Salisbury, E., Henning, C., \& Holdford, R. (2009). Fathering by partner-abusive men: Attitudes on children's exposure to violence and risk factors for child abuse. Child Maltreatment, 14, 232-242. doi:10.1177/1077559509338407

Scott, K. L., \& Coolbear, J. (2001). The Psychosocial Risk Assessment Interview. Toronto, ON: Hospital for Sick Children.

Scott, K. L., \& Crooks, C. (2004). Effecting change in maltreating fathers: Critical principles for intervention planning. Clinical Psychology: Science and Practice, 11, 95-111. doi:10.1093/clipsy/bph058

Scott, K. L., \& Crooks, C. (2007). Preliminary evaluation of an intervention program for maltreating fathers. Brief Treatment and Crisis Intervention, 7, 224-238. doi:10.1093/brief-treatment/mhm007

Scott, K. L., \& Mederos, F. (2011). Parenting interventions for men who batter. National Online Resource Center on Violence Against Women.

Sidebotham, P., Bailey, S., Belderson, P., \& Brandon, M. (2011). Fatal child maltreatment in England, 2005-2009. Child Abuse \& Neglect, 35, 299-306. doi:10.1016/j.chiabu.2011.01.005

Sinha, M. (2012). Family violence in Canada: A statistical profile, 2010. Juristat: Canadian Centre for Justice Statistics, $1 A-68$.

Sloan, M. P., \& Meier, J. H. (1983). Typology for parents of abused children. Child Abuse \&Neglect, 7, 443-450. doi:10.1016/0145-2134(83)90051-0

Smith Slep, A. M., \& O'Leary, S. G. (2005). Parent and partner violence in families with young children: Rates, patterns, and connections. Journal of Consulting and Clinical Psychology, 73, 435-444. doi:10.1037/0022-006X.73.3.435

Statistics Canada. (2009). Family violence in Canada: A statistical profile. Ottawa, Canada: Statistics Canada, 85-224X. Retrieved from http://www.statcan.gc.ca/pub/85-224-x/85-224-x2010000-eng.pdf

Stewart, L. (2004). Fathers'recognition and prioritization of needs with the father-child relationship: Development and validation of the Balance of Needs Measure (BONM) (Unpublished master's thesis). University of Toronto, Canada.

Stith, S. M., Liu, T., Davies, L. C., Boykin, E. L., Alder, M. C., Harris, J. M., . . Dees, J. (2009). Risk factors in child maltreatment: A meta-analytic review of the literature. Aggression and Violent Behavior, 14, 13-29. doi:10.1016/j. avb.2006.03.006

Strega, S., Fleet, C., Brown, L., Dominelli, L., Callahan, M., \& Walmsley, C. (2008). Connecting father absence and mother blame in child welfare policies and practice. Children and Youth Services Review, 30, 705-716. doi:http:// dx.doi.org.myaccess.library.utoronto.ca/10.1016/j.childyouth.2007.11.012

Stover, C. S. (2013). Fathers for change: A new approach to working with fathers who perpetrate intimate partner violence. Journal of the American Academy of Psychiatry and the Law Online, 41, 65-71. Retrieved from http:// simplelink.library.utoronto.ca/url.cfm/433585

Stover, C. S., Easton, C., \& McMahon, T. (2013). Parenting of men with co-occurring intimate partner violence and substance abuse. Journal of Interpersonal Violence, 28, 2290-2314. doi:10.1177/0886260512475312

Tolan, P., Gorman-Smith, D., \& Henry, D. (2006). Family violence. Annual Reviews of Psychology, 57, 557-583. doi:10.1146/annurev.psych.57.102904.190110

Trocmé, N., Fallon, B., MacLaurin, B., Sinha, V., Black, T., Fast, E., . . Holroyd, H. (2010). Canadian incidence study of reported child abuse and neglect 2008 (CIS 2008):Major findings. Ottawa, ON: Minister of Public Works and Government Services Canada.

Williams, T. Y., Boyd, J. C., Cascardi, M. A. \& Poythress, N. (1996). Factor structure and convergent validity of the Aggression Questionnaire in an offender population. Psychological Assessment, 8, 398-403. doi:10.1037/1040-3590.8.4.398

Yampolskaya, S., Greenbaum, P. E., \& Berson, I. R. (2009). Profiles of child maltreatment perpetrators and risk for fatal assault: A latent class analysis. Journal of Family Violence, 24, 337-348. doi:10.1007/s10896-009-9233-8

U.S. Department of Health and Human Services, Administration for Children and Families, Administration on Children, Youth and Families, Children's Bureau. (2013). Child maltreatment 2012. Retrieved from http://www.acf.hhs. gov/programs/cb/research-data-technology/statistics-research/child-maltreatment

Zanoni, L., Warburton, W., Bussey, K., \& McMaugh, A. (2013). Fathers as 'core business' in child welfare practice and research: An interdisciplinary review. Children and Youth Services Review, 35, 1055-1070. doi:http://dx.doi. org/10.1016/j.childyouth.2013.04.018 